\title{
Distribution, seasonal pattern, flux and contamination source of pesticides and nonylphenol residues in Kurose River water, Higashi-Hiroshima, Japan
}

\author{
Aly Soliman Hamed Derbalah, Nobutake Nakatani and Hiroshi Sakugawa* \\ Graduate School of Biosphere Sciences, Hiroshima University, \\ 1-7-1 Kagamiyama, Higashi-Hiroshima 739-8521, Japan
}

(Received June 5, 2002; Accepted November 14, 2002)

\begin{abstract}
Distributions, seasonal variation, flux and contamination source of pesticides and nonylphenol were examined during the period from April 2001 to January 2002 at 5 sites (Namitakiji, Tokumasa-Kami, Izumi, Ochiai and Hinotsume) in Kurose River water, Higashi-Hiroshima, Japan. Water samples were collected monthly and subjected to solid phase extraction followed by GC-MS analysis. Nineteen pesticide compounds were detected and isoprothiolane (37 ng/l), fenitrothion (35) and iprodione (34) showed the highest mean concentrations (as 5 site averages), while pencycuron (5), diazinon (6), tolclofos- methyl (7) and dithiopyr (8) were the compounds of lowest mean concentrations. Nonylphenol, which is a degradation product of a nonylphenolpolyethoxylates that are used in a wide range of industrial and household products, had an average concentration of $305 \mathrm{ng} / \mathrm{l}$. At each of the five sites, its concentration was greater than individual pesticides. The concentration levels of pesticides and nonylphenol were highest at Izumi (the downtown site of Higashi- Hiroshima) and were lowest at Namitakiji and Tokumasa-Kami (upstream sites). Concentrations and fluxes of both compounds tended to be higher during spring to summer and low during fall to winter at most of the sites. The total pesticides concentration was poorly correlated with nonylphenol concentration. A statistical analysis of water quality data suggested that their main sources appear to be different such as agricultural activity for pesticides and waste water discharge for nonylphenol.
\end{abstract}

\section{INTRODUCTION}

Agricultural pesticides significantly improve crop yields and pesticides protect against pests. Japan is one of the main users of pesticides worldwide, with more than 450 active products distributed among 5400 commercial products (Japan Plant Protection Association, 2000). On the other hand, pesticides have become universal contaminants found in all segments of the environment and create many hazards to the environment and human health. Pesticide contamination in fresh water, which has emerged as an important environmental problem in the last few decades, is causing concern with respect to long-term and lowdose effects of pesticides on public health as well as non-target species (Sudo et al., 2002). Pesticides with different type such as insecticides including fenitrothion, diazinon, chloropyrifos, isophenphos and pyridaphenthion, herbicides including simazine, propyzamide, pendimethalin and butamifos, and fungicides including flutolanil, mepronil, tolclofos-methyl, mepronil, iprodione, isoxathion, chlorothalonil, isoprothiolane, and pencycuron were considered to be common pesticides found in the environment, Japan (Numabe et al., 1992; Odanaka et al., 1994; Okumura and Nishikawa, 1995; Itagaki et al., 2000; Kondoh et al., 2001; Tanabe et al., 2001; Sudo et al., 2002). Some pesticides such as fenitrothion, iprodione, pedimethalin and simazine are also suspected as endocrine disrupters (Crisp et al., 1998; Tamura 
et al., 2001).

Pesticides are primarily moved from agricultural fields to streams by surface runoff (Richards and Baker, 1993). The amount and kind of pesticides in water of a given area depends largely on the production intensity and kind of crops. However, the transport of pesticides out of their application area results in the presence and accumulation of these compounds in many parts of hydrosphere. For example, atmospheric precipitation is an important route of transport of pesticides, resulting in contamination of environmental waters far from agricultural areas (Majewski et al., 2000). The amount of pesticides lost from fields and transported to streams depends on several factors, including soil characteristics, topography, weather, agricultural management practices and the chemical and environmental properties of individual pesticides (Leonard, 1990). Site selection is important for pesticides monitoring because the types of pesticides used are directly related to the land use and the type of agricultural system. Thus, understanding the relation between land use and pesticide use is the key to evaluating the causes of pesticides occurrence in streams (Larson et al., 1999).

Nonylphenol polyethoxylates (NPEOs) is a major class of non-ionic surfactants used in household, paints, and pesticides and in industrial processes such as paper and petroleum production (Fairchild et al., 1999). Nonylphenol is the most toxic and refractory metabolite of NPEOs and can cause several hazards to aquatic ecosystem (McLeese et al., 1981; Ahel et al., 1987). Pesticides are though to be a secondary source of nonylphenol contamination in natural water because NPEOs are used as adjuvants in pesticide formulations (Sundaram et al., 1980; Fairchild et al., 1999; Scott and Jones, 2000; Thomas et al., 2001). Nonylphenol is known to be an endocrine disrupter (Fairchild et al., 1999; Scott and Jones, 2000). In order to assess the risk of nonylphenol, its presence and fate in the environment must be known (Mol et al., 2000).

Water quality parameters may have a strong effect on the occurrence of pesticides in natural water (Samia El-Kabbany et al., 2000). Water temperature has a strong influence on the acclimation period of microorganisms and its biodegradation rate of NPEOs to nonylphenol; the biodegradation process takes $15-20$ days at $7^{\circ} \mathrm{C}$ and $2-3$ days at $21^{\circ} \mathrm{C}$ (Manzano et al., 1999). The stability of pesticides in water is strongly dependent on $\mathrm{pH}$ and is highest in slightly acidic water ( $\mathrm{pH} 4-6)$ (Petroff, 2000). Thus, because of these environmental factors, some heavily used compounds end up with low concentration while other slightly used compounds end up with high concentrations. Also dissolved organic carbon (DOC) may be an indicator of water pollution by organic compounds such as our target compounds (pesticides and nonylphenol) (Castilho et al., 2000).

In this study, we attempted (1) to develop a practical method for monitoring pesticides and nonylphenol, (2) to evaluate the distribution and seasonal patterns of pesticides and nonylphenol occurrence in Kurose River, (3) to determine the discharging amount of these contaminants at each site in Kurose River, (4) and to elucidate the contamination sources of several common pesticides (pencycuron, simazine, propyzamide, diazinon, chlorothalonil, terbucarb, tolclofos-methyl, metalaxyl, bensulide, dithiopyr, fenitrothion, chloropyrifos, pendimethalin, methyldymron, captan, isophenphos, naporpamide, butamifos, flutolanil, isoprothiolane, triclopyr-ester, isoxathion mepronil, iprodione and pyridaphenthion) and nonylphenol residues in Hiroshima prefecture.

\section{MATERials AND METhODS}

\section{Chemicals}

A mixture of 25 pesticide standard compounds (pencycuron, simazine, propyzamide, diazinon, chlorothalonil, terbucarb, tolclofos-methyl, metalaxyl, bensulide, dithiopyr, fenitrothion, chloropyrifos, pendimethalin, methyldymron, captan, isophenphos, naporpamide, butamifos, flutolanil, isoprothiolane, triclopyr-ester, isoxathion mepronil, iprodione and pyridaphenthion) was obtained from Kanto Com- 
pany, Japan. A nonylphenol, technical mixture of ring and chain isomers was obtained from Aldrich Company, U.S.A. Working standard solutions of these compounds were prepared by making appropriate dilutions in acetone and stored in a refrigerator at $4^{\circ} \mathrm{C}$. Pesticide analytical grade solvents, such as methanol, acetone, and dichloromethane were obtained from Wako Company, Japan. The internal standard phenanthrine- $\mathrm{d}_{10}(97.5 \%$ purity $)$ was obtained from Supelco Company U.S.A. Acetic acid ( $99.7 \%$ purity) was obtained from Katayama Company, Japan.

\section{Sites and target compounds selection}

Kurose River is located in Hiroshima prefecture, and is about $43 \mathrm{~km}$ long. Its runs urban and agricultural areas of the Kamo plateau, including Higashi-Hiroshima City and Kurose Town, and flows into the Seto inland Sea. It has a water collection area of about $250 \mathrm{~km}^{2}$. The runoff from agricultural fields and wastewater containing industrial and household pollutants flows into this River. Higashi-Hiroshima city is considered the granary of Hiroshima prefecture. For example, it has the largest rice production of 86 cities, towns and villages in the prefecture (Hiroshima Prefecture Office, 2002). Also there are many crops cultivated in the city such as wheat, bean potato, sweat potato and other vegetables as well as ornamental plants. In order to monitor the pesticides and nonylphenol levels in the present study, 5 sites (Namitakiji, Tokumasa-Kami, Izumi, Ochiai and Hinotsume) were established at Kurose River in Higashi-Hiroshima City as shown in Fig. 1. Sampling sites were selected in different agricultural and urban basins along the river. The TokumasaKami, Ochiai and Hinotsume sites were located near agricultural areas especially near rice field and low resident population area. The Ochiai site is next to water treatment facility that serves the City of Higashi Hiroshima. The Izumi site is located nears a high density residential and industrial area. The Namitakiji site is the most upstream site and is located away from agricultural and urban areas. Three classes of pesticides were investigated: insecticides, herbicides and fungicides.

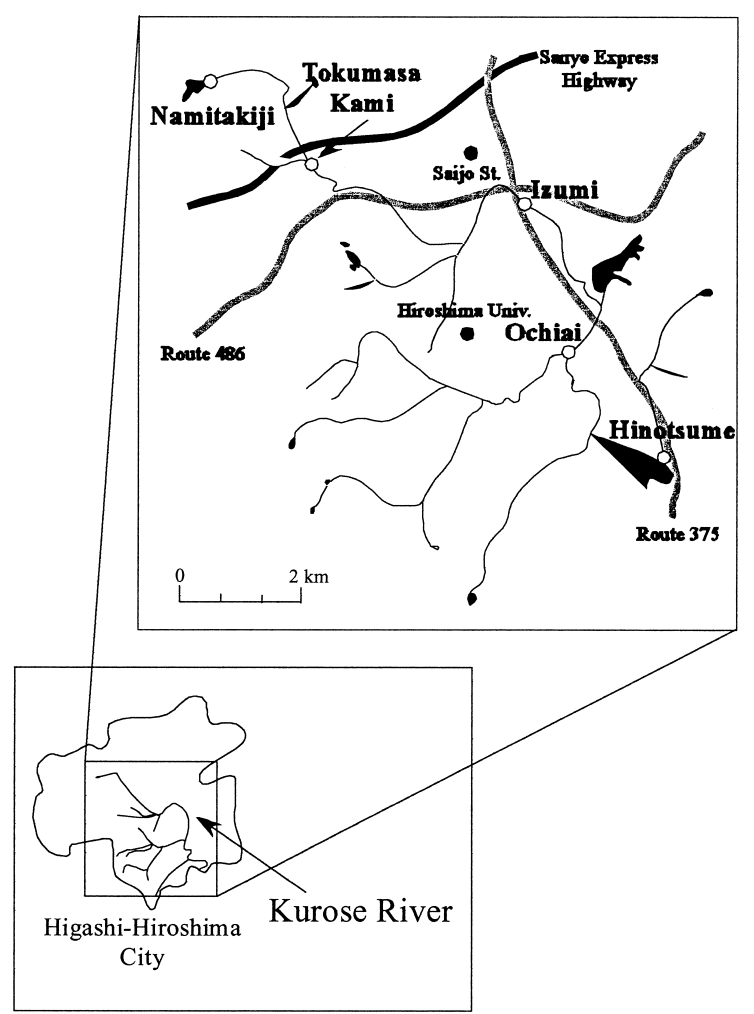

Fig. 1. Locations of sampling sites in Kurose River.

Representatives of each class were selected based on amount of their use in Hiroshima prefecture from October 1999 to September 2000 (JPPA, 2000), and on their potential environmental significance. Monthly precipitation data in HigashiHiroshima City were obtained from Hiroshima University Meteorological Data Acquisition System.

Estimated annual use of pesticides in HigashiHiroshima was calculated by using the ratio of agricultural area in Higashi-Hiroshima (4560 ha.) to agricultural area of Hiroshima prefecture (65200 ha.), which data were taken from the report of Hiroshima prefecture office (2002) as well as the data of pesticides agricultural use in Hiroshima prefecture (JPPA, 2000). Terbucarb was excluded for calculating the flux because no information about the annual use of this compound in Hiroshima prefecture. 


\section{Sampling and extraction method}

Water samples were collected from the river at monthly intervals with 1 liter precleaned amber glass bottles. The samples were protected from exposure to light. They were kept at $4^{\circ} \mathrm{C}$ in ice cooler until delivered to analytical laboratory. Water flow rate was measured using a Hiroi-type water flow meter (Mikasa, Japan). At the sampling sites, conductivity and $\mathrm{pH}$ were measured with a D-24 pH/Conductivity meter, (Horiba, Ltd.) Japan. Water temperature was measured with a mercury thermometer. Water samples were filtered through glass fiber filters (GC-50, diameter: 47 $\mathrm{mm}$; pore size: $0.5 \mu \mathrm{m}$, Advantec). The glass fiber filters were ultrasonically extracted with acetone and combined with filtered samples. Samples were acidified with acetic acid to $\mathrm{pH} 3.0$ to attaining a high recovery of the target compounds.

Target compounds were extracted from the acidified samples using an automated solid phase extraction (SPE) apparatus according to the method of Itagaki et al. (2000) with some modifications. The cartridges (OASIS $60 \mathrm{mg}$ Waters, Milford Ma, U.S.A.) were washed sequentially with $5 \mathrm{ml}$ dichloromethane, $5 \mathrm{ml}$ methanol and 5 ml Milli-Q water (Millipore. Co. Ltd. U.S.A.) under vacuum before use. A one-liter aliquot of the acidified samples was passed through the cartridges at a flow rate $10-20 \mathrm{ml} / \mathrm{min}$ and then the cartridges were washed with $10 \mathrm{ml}$ Milli-Q water. Air was the sucked through the cartridges for about 30 min with a vacuum to remove the water. The target compounds were eluted with $5 \mathrm{ml}$ dichloromethane. The solvent was evaporated

Table 1. Type, retention time, quantitation and confirmation ions for target compounds in SIM mode of GC-MS analysis

\begin{tabular}{|c|c|c|c|c|c|}
\hline & Compound name & Type & Retention time (min) & Quantitation ion $(\mathrm{m} / \mathrm{z})$ & Confirmation ion $(\mathrm{m} / \mathrm{z})$ \\
\hline 1 & Pencycuron & Fungicide & 18.60 & 125 & 180 \\
\hline 2 & Simazine & Herbicide & 19.45 & 201 & 186 \\
\hline 3 & Propyzamide & Herbicide & 20.08 & 173 & 175 \\
\hline 4 & Diazinon & Insecticide & 20.33 & 137 & 179 \\
\hline 5 & Chlorothalonil & Fungicide & 20.66 & 266 & 264 \\
\hline 6 & Terbucarb & Herbicide & 21.57 & 205 & 220 \\
\hline 7 & Tolclofos-methyl & Fungicide & 21.72 & 265 & 267 \\
\hline 8 & Metalaxyl & Fungicide & 21.94 & 206 & 132 \\
\hline 9 & Bensulide & Fungicide & 21.94 & 77 & 131 \\
\hline 10 & Dithiopyr & Herbicide & 22.23 & 354 & 306 \\
\hline 11 & Fenitrothion & Insecticide & 22.32 & 125 & 109 \\
\hline 12 & Chloropyrifos & Insecticide & 22.88 & 199 & 97 \\
\hline 13 & Pendimethalin & Herbicide & 23.71 & 252 & 253 \\
\hline 14 & Methyldymron & Herbicide & 23.87 & 107 & 106 \\
\hline 15 & Captan & Fungicide & 23.91 & 79 & 149 \\
\hline 16 & Isophenphos & Insecticide & 23.95 & 58 & 121 \\
\hline 17 & Napropamide & Herbicide & 24.94 & 72 & 100 \\
\hline 18 & Butamifos & Herbicide & 24.94 & 286 & 200 \\
\hline 19 & Flutolanil & Fungicide & 24.98 & 173 & 145 \\
\hline 20 & Isoprothiolane & Fungicide & 25.10 & 118 & 162 \\
\hline 21 & Triclopyr-ester & Herbicide & 25.57 & 57 & 85 \\
\hline 22 & Isoxathion & Fungicide & 25.71 & 105 & 177 \\
\hline 23 & Mepronil & Fungicide & 26.56 & 119 & 91 \\
\hline 24 & Iprodione & Fungicide & 28.10 & 314 & 316 \\
\hline 25 & Pyridaphenthion & Insecticide & 28.23 & 97 & 77 \\
\hline 26 & Nonylphenol isomer-1 & - & 18.89 & 135 & 107 \\
\hline 27 & Nonylphenol isomer-2 & - & 19.00 & 135 & 107 \\
\hline 28 & Nonylphenol isomer-3 & - & 19.56 & 135 & 107 \\
\hline
\end{tabular}


under a stream of nitrogen until almost complete dryness and the residue was re-dissolved in $1 \mathrm{ml}$ acetone. An internal standard $(0.5 \mu \mathrm{g} / \mathrm{ml})$ was added into the solution and final volume was adjusted to $100 \mu \mathrm{l}$. Then $5 \mu \mathrm{l}$ of the solution was analyzed by GC-MS.

\section{GC-MS analysis}

Samples were analyzed with a HewlettPackard HP 5973 series gas chromatograph equipped with HP 5973 mass selective detector, and an Agilent 6890 series injector was used for an injection of the sample. The column was a refused silica capillary HP-5MS chromatographic column (30 m long $\times 0.25 \mathrm{~mm}$ I.D., film thickness $0.25 \mu \mathrm{m})$. The oven temperature was programmed to hold for $2 \mathrm{~min}$ at $60^{\circ} \mathrm{C}$ and then increased to $280^{\circ} \mathrm{C}$ at the rate of $8^{\circ} \mathrm{C} \mathrm{min}^{-1}$ and hold at $280^{\circ} \mathrm{C}$ for $8 \mathrm{~min}$. The injector and transfer line temperature were 250 and $280^{\circ} \mathrm{C}$, respectively. The carrier gas (helium) was used a constant flow rate $(1 \mathrm{ml} / \mathrm{min})$. Standard and extracted solutions were injected in the splitless mode.

Target compounds were quantitatively determined in the selective ion mode (SIM) using the peak area ratio of target compounds to internal standard. The main ions of the target compounds in mass spectrometry are shown in Table 1 . The total pesticide concentration was calculated by summing the concentration of individual compounds. The highest three isomer peaks of the nonylphenol mixture were selected for nonylphenol determination and the concentration of nonylphenol was calculated by summing the concentration of these isomers.

The target compounds were spiked into 200 $\mathrm{ml}$ Milli-Q water at levels of $1 \mu \mathrm{g} / \mathrm{l}$ and $0.1 \mu \mathrm{g} / \mathrm{l}$ for recovery and detection limit calculation, respectively. Another recovery test was carried out using $1 \mathrm{~L}$ spike volume at the same concentration level. Subsequently the water was acidified to $\mathrm{pH}$ 3.0 immediately after this operation; water samples were extracted with an automated solid phase extraction (SPE) apparatus. The detection limit was taken as concentration giving a signal-to-noise ratio of three, according to the method of Azevedo et al. (2000). The test determining the recovery efficiency and the detection limit were repeated five times to obtain accurate values.

\section{Water quality parameters}

Water quality parameters, such as, DOC, anions and cations were analyzed at all the sampling sites. Anions $\left(\mathrm{Cl}^{-}, \mathrm{NO}_{2}^{-}, \mathrm{NO}_{3}{ }^{-}\right.$and $\left.\mathrm{SO}_{4}{ }^{2-}\right)$ and cations $\left(\mathrm{Na}^{+}, \mathrm{K}^{+}, \mathrm{NH}_{4}^{+}, \mathrm{Ca}^{2+}\right.$ and $\left.\mathrm{Mg}^{2+}\right)$ were measured by ion chromatography (Dionex, DX500) with the column of Ion Pac AS11 for anions and Ion Pac CS12A for cations. DOC was measured by TOC 5000-A (Shimadzu Comp. Japan). DOC, anions and cations were measured after filtration of water samples.

\section{Flux calculations}

The flux is defined as the mass of the compound transported in stream in specific time period. The flux of target compounds at each sampling point was estimated as the product of the compound concentration and the site discharge (water flow rate) for each month. The monthly fluxes were summed to give the total flux over the study period according to the method of Larson et al. (1995). The Hiroshima prefecture office's continuous monitoring data of water flow rates collected at near Ochiai site was used for calculating the flux of individual pesticides.

\section{Statistical analysis}

A principle component analysis (PCA) was conducted with the SPSS Base 7.5 (SPSS Inc, U.S.A.) to identify underlying factors that explain the patterns of correlations within a set of observed variables and to generate hypotheses regarding to the sources of nonylphenol and pesticide contamination. The method of factors extraction was principle component and the method of factors rotation was the orthogonal varimax. Coefficient values lower than 0.5 were excluded.

\section{RESUlTS AND DISCUSSION}

\section{Water quality parameters}

The main $\mathrm{pH}$ at all sampling sites ranged from 


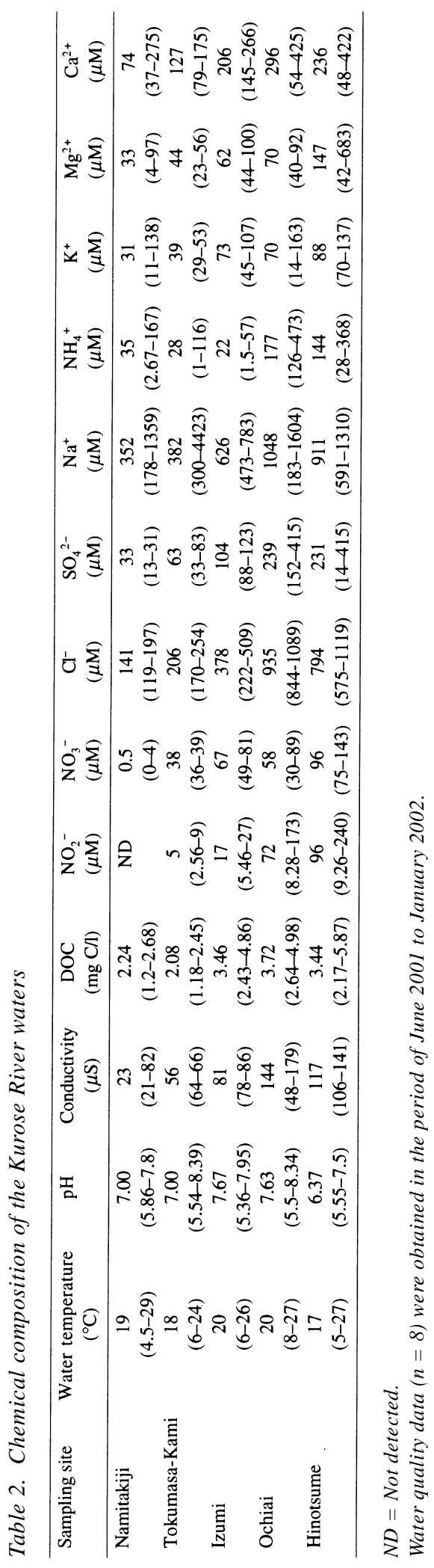

6.37 to 7.00 (Table 2), which is slightly higher than the ideal $\mathrm{pH}$ for pesticides stability in water (Petroff, 2000). Water temperature ranged from $19-29^{\circ} \mathrm{C}$ at all sites during the period from May to October 2001, which may accelerate biodegradation of NPEOs to nonylphenol (Manzano et al., 1999). The Izumi, Ochiai and Hinotsume sites appeared to be the most heavily contaminated sites with high concentrations of DOC. They also had high concentrations of various anions $\left(\mathrm{Cl}^{-}, \mathrm{NO}_{2}^{-}\right.$, $\mathrm{NO}_{3}{ }^{-}$and $\left.\mathrm{SO}_{4}{ }^{2-}\right)$ and cations $\left(\mathrm{Na}^{+}, \mathrm{K}^{+}, \mathrm{NH}_{4}{ }^{+}, \mathrm{Ca}^{2+}\right.$ and $\left.\mathrm{Mg}^{2+}\right)$. Among cations and anions, $\mathrm{Na}^{+}$and $\mathrm{Cl}^{-}$were detected with higher concentration comparing with other anions and cations. $\mathrm{NO}_{3}{ }^{-}$and $\mathrm{NO}_{2}^{-}$, which are considered to be one of the main sources of $\mathrm{OH}$ radical in natural water (Mopper and Zhou, 1990), were detected with higher concentrations at these heavily contaminated sites. Therefore $\mathrm{NO}_{3}{ }^{-}$and $\mathrm{NO}_{2}^{-}$may have roles the photodegradation of organic compounds and may affect their lifetimes and concentrations in the stream. $\mathrm{NH}_{4}{ }^{+}$concentrations were high at Ochiai and Hinotsume sites, apparently as a result of their use as fertilizers in agricultural fields. Conductivity was associated with anion and cation concentrations at all sites.

\section{Efficiency of the method}

All 25 authentic pesticides and nonylphenol isomers were separated by GC column and eluted in a reasonable time. Using solid phase extraction with a $200 \mathrm{ml}$ spike volume, recoveries of the most authentic samples were in the range $70-107 \%$ (Table 3). Lower recoveries were obtained for mepronil and iprodione (63 and 61\%, respectively). When the spike volume increased to $1 \mathrm{~L}$, recoveries of most samples remained in the same range (70 to $109 \%$ ) although the recoveries of pendimethalin and isophenphos dropped to 65 and $64 \%$, respectively. Because the recoveries of all the targeted compounds were high, the recovery efficiencies were not used to correct the analytical concentrations.

The relative standard deviation was around $10 \%$ but it was always below $30 \%$ in accordance with the US Environmental Protection Agency 
Table 3. Recovery percentage, standard deviation, relative standard deviation and limits of detection of target compounds in this study

\begin{tabular}{|c|c|c|c|c|}
\hline Compound name & $\mathrm{R}(\%)$ & $\mathrm{SD}(\mathrm{ng} / \mathrm{l})$ & RSD (\%) & $\mathrm{DL}(\mathrm{ng} / \mathrm{l})$ \\
\hline Pencycuron & 82 & 10.6 & 3.5 & 5 \\
\hline Simazine & 91 & 5.7 & 2.5 & 24 \\
\hline Propyzamide & 82 & 4.6 & 4.2 & 12 \\
\hline Diazinon & 85 & 7.0 & 6.8 & 2 \\
\hline Chlorothalonil & 96 & 11.6 & 2.9 & 5 \\
\hline Terbucarb & 83 & 5.6 & 4.7 & 20 \\
\hline Tolclofos-methyl & 79 & 7.8 & 4.4 & 6 \\
\hline Metalaxyl & 70 & 6.9 & 4.5 & 20 \\
\hline Dithiopyr & 77 & 6.4 & 9.1 & 9 \\
\hline Fenitrothion & 101 & 14 & 9.8 & 21 \\
\hline Bensulide & 97 & 20.0 & 1.9 & 2 \\
\hline Chloropyrifos & 78 & 3.6 & 5.5 & 9 \\
\hline Pendimethalin & 84 & 8.6 & 10.4 & 8 \\
\hline Methyldymron & 94 & 17.4 & 2.6 & 6 \\
\hline Captan & 70 & 4.9 & 3.5 & 9 \\
\hline Isophenphos & 76 & 5.0 & 2.2 & 2 \\
\hline Napropamide & 96 & 3.4 & 12.9 & 18 \\
\hline Butamifos & 107 & 19.6 & 1.6 & 7 \\
\hline Flutolanil & 83 & 3.4 & 5.7 & 4 \\
\hline Isoprothiolane & 74 & 9.4 & 1.8 & 8 \\
\hline Triclopyr-ester & 70 & 2.7 & 3.4 & 15 \\
\hline Isoxathion & 76 & 4.9 & 3.1 & 9 \\
\hline Mepronil & 61 & 4.7 & 3.1 & 12 \\
\hline Iprodione & 63 & 3.7 & 3.0 & 30 \\
\hline Pyridaphenthion & 70 & 6.7 & 4.8 & 9 \\
\hline NP-isomer1 & 82 & 3.5 & 2.1 & 10 \\
\hline NP-isomer2 & 84 & 15.5 & 9.1 & 18 \\
\hline NP-isomer3 & 97 & 15.6 & 8.1 & 15 \\
\hline
\end{tabular}

$R=$ Recovery $; S D=$ Standard deviation $; R S D=$ Relative standard deviation $; D L=$ Detection limits. Number of replicates $=5$.

method (Azevedo et al., 2000). Detection limits of the 25 pesticide compounds and nonylphenol ranged from 2 to $30 \mathrm{ng} / \mathrm{l}$.

\section{Pesticides}

A total of nineteen pesticides were detected at the five sites (Fig. 2). Among the detected pesticides, isoprothiolane (44\%), flutolanil (38\%), fenitrothion $(34 \%)$, terbucarb $(28 \%)$ and methyldymron (26\%) were detected with relatively high frequency comparing with the others pesticides. In the most crops in agricultural fields, isoprothiolane, flutolanil, are used to control a wide range of fungal diseases and methyldymron and terbucarb are used for weed control. Fenitrothion is a powerful insecticide that is widely used against many insects and crustaceans. Fenitrothion and isoporthiolane have also been detected with high frequency by other investigators in Japan (Numabe et al., 1992; Itagaki et al., 2000; Kondoh et al., 2001; Tanabe et al., 2001; Sudo et al., 2002). The pesticides with highest mean concentrations were isoprothiolane, fenitrothion and iprodione (37, 35 and $34 \mathrm{ng} / \mathrm{l}$, respectively) (as 5 sites average), while those with lowest mean concentrations were pencycuron, diazinon, tolclofos-methyl and dithiopyr (5, 6, 7 and $8 \mathrm{ng} / \mathrm{l}$, respectively) (Table 4). This implies that, for many of these pesticides, factors such as soil characteristics, weather and agricultural management practices, may be more influential than their chemical and physical properties (e.g., wa- 


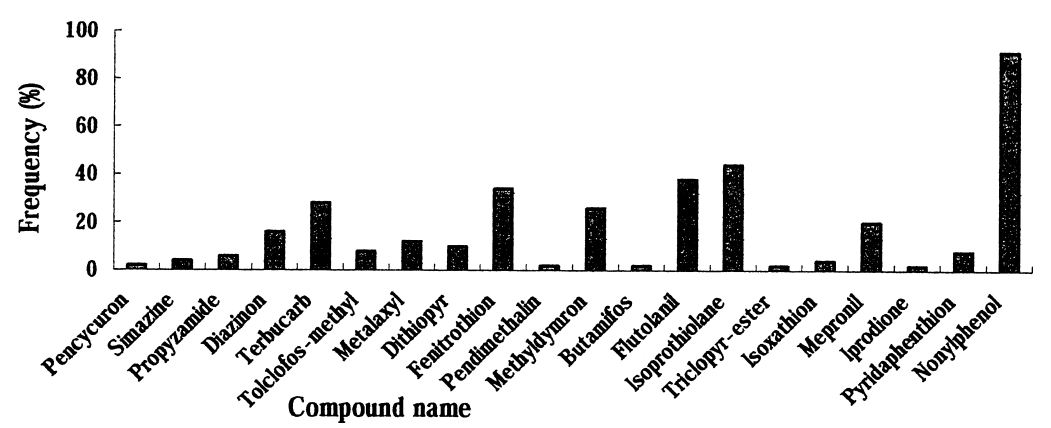

Fig. 2. Detection frequency of pesticides and nonylphenol during the study period in Kurose River. Detection frequency $(\%)=($ number of samples detecting the compound $) /($ number of samples analyzed $)$.

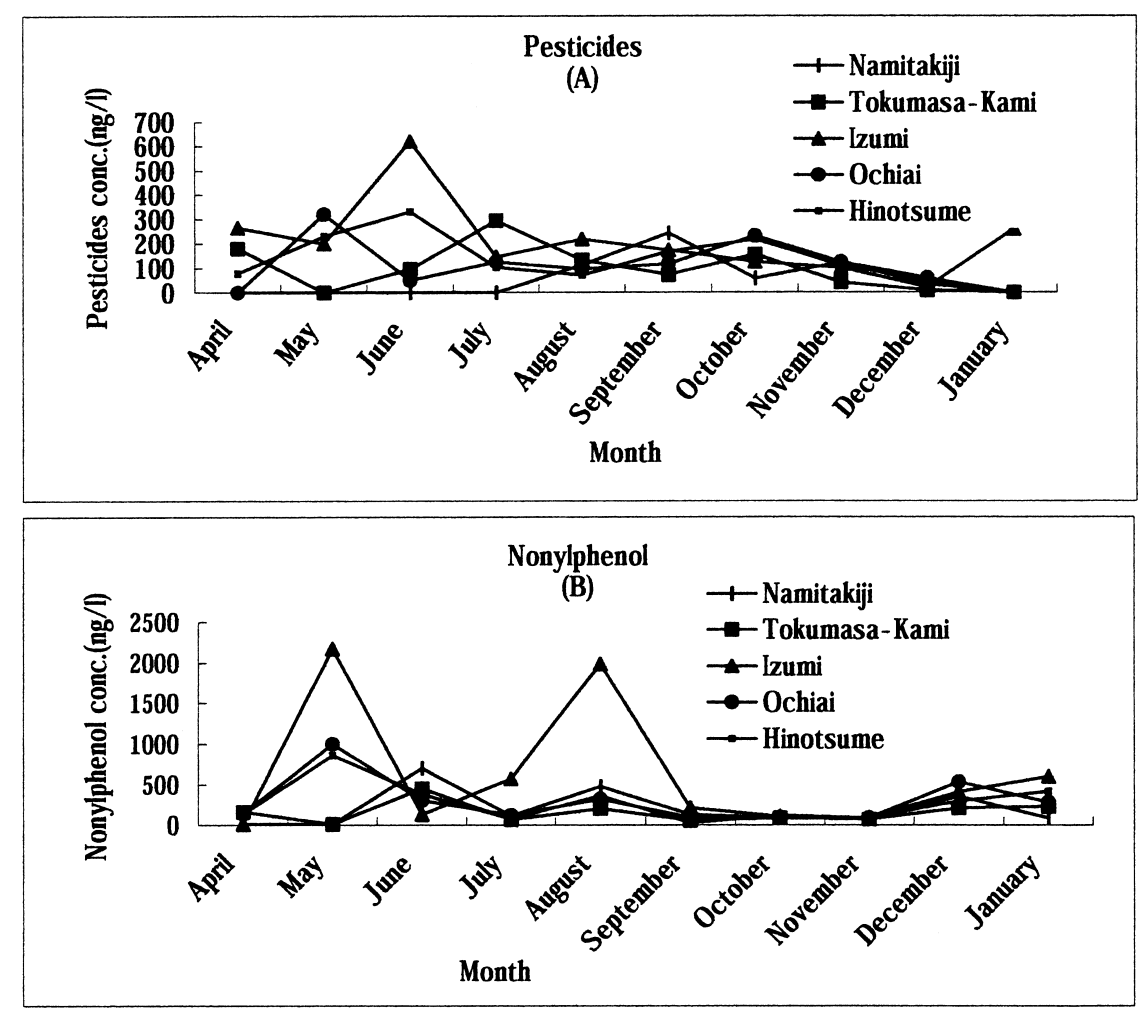

Fig. 3. Monthly variation of pesticides and nonylphenol concentrations at sampling sites in Kurose River.

ter solubility) in their movement from agricultural fields to the river. The types of detected pesticides in this study, and their concentrations are generally the same as those reported in other river waters in Japan. The concentration of fenitrothion, diazinon and isoprothiolane in Seta river water were $0.006,0.023$ and $0.331 \mu \mathrm{g} / \mathrm{l}$, respectively
(Sudo et al., 2002). Itagaki et al. (2000) reported that fenitrothion was detected with $0.008 \mu \mathrm{g} / \mathrm{l}$ of mean concentration in Minaga river water, while Numabe et al. (1992) reported that fenitrothion concentration was $0.025 \mu \mathrm{g} / \mathrm{l}$ in Kozakura river water. The concentration levels of simazine $(0.024$ $\mu \mathrm{g} / \mathrm{l})$, diazinon $(0.024 \mu \mathrm{g} / \mathrm{l})$, fenitrothion $(0.036$ 
Table 4. Mean, minimum and maximum concentrations of pesticides and nonylphenol detected at various sites of Kurose River during April 2001-January 2002

\begin{tabular}{|c|c|c|c|c|c|c|}
\hline \multirow[t]{2}{*}{ Compound name } & \multicolumn{5}{|c|}{ Site name } & \multirow[t]{2}{*}{ Average } \\
\hline & Namitakiji & Tokumasa-Kami & Izumi & Ochiai & Hinotsume & \\
\hline Pencycuron & $<5$ & $<5$ & $<5$ & $<5$ & $6(<5-12)$ & 5 \\
\hline Simazine & $<24$ & $<24$ & $25(<24-37)$ & $25(<24-35)$ & $<24$ & 24 \\
\hline Propyzamide & $<12$ & $<12$ & $14(<12-27)$ & $<12$ & $<12$ & 12 \\
\hline Diazinon & $<2$ & $3(<2-10)$ & $7(<2-4)$ & $16(<2-89)$ & $<2$ & 6 \\
\hline Terbucarb & $<20$ & $24(<20-61)$ & $22(<20-41)$ & $21(<20-31)$ & $28(<20-97)$ & 23 \\
\hline Tolclofos-methyl & $<6$ & $<6$ & $<6$ & $<6$ & $9(<6-25)$ & 7 \\
\hline Metalaxyl & $<20$ & $<20$ & $32(<20-99)$ & $35(<20-101)$ & $27(<20-80)$ & 27 \\
\hline Dithiopyr & $<9$ & $<9$ & $11(<9-25)$ & $10(<9-25)$ & $13(<9-49)$ & 8 \\
\hline Fenitrothion & $30(<21-65)$ & $39(<21-86)$ & $54(<21-304)$ & $<21$ & $30(<21-56)$ & 35 \\
\hline Pendimethalin & $<8$ & $<8$ & $11(<8-35)$ & $<8$ & $<8$ & 9 \\
\hline Methydymron & $19(<6-98)$ & $13(<6-52)$ & $28(<6-96)$ & $23(<6-142)$ & $17(<6-110)$ & 20 \\
\hline Butamifos & $<7$ & $<7$ & $15(<7-82)$ & $<7$ & $<7$ & 9 \\
\hline Flutolanil & $6(<4-25)$ & $10(<4-38)$ & $26(<4-113)$ & $21(<4-56)$ & $19(<4-41)$ & 16 \\
\hline Isoprothiolane & $8(<8-9)$ & $39(<8-244)$ & $79(<8-567)$ & $17(<8-84)$ & $44(<8-299)$ & 37 \\
\hline Triclopyr-ester & $<15$ & $<15$ & $16(<15-24)$ & $<15$ & $<15$ & 15 \\
\hline Isoxathion & $<9$ & $<9$ & $13(<9-20)$ & $10(<9-16)$ & $<9$ & 10 \\
\hline Mepronil & $<12$ & $18(<12-56)$ & $15(<12-26)$ & $13(<12-23)$ & $13(<12-21)$ & 14 \\
\hline Iprodione & $51(<30-244)$ & $<30$ & $<30$ & $<30$ & $<30$ & 34 \\
\hline Pyridaphenthion & $<9$ & $<9$ & $<9$ & $23(<9-98)$ & $10(<9-23)$ & 12 \\
\hline Total pesticides & 272 & 300 & 418 & 318 & 323 & 326 \\
\hline Nonylphenol & $207(<14-700)$ & $136(<14-250)$ & $629(<14-2170)$ & 285 (92-995) & $269(28-858)$ & 305 \\
\hline
\end{tabular}

Unit $=n g / l$.

$\mu \mathrm{g} / \mathrm{l})$, pyridaphenthion $(0.022 \mu \mathrm{g} / \mathrm{l})$, flutolanil $(0.021 \mu \mathrm{g} / \mathrm{l})$, and mepronil $(0.063 \mu \mathrm{g} / \mathrm{l})$ in Shinano river water were reported by Tanabe et al. (2001). The concentration level of diazinon $(0.016 \mu \mathrm{g} / \mathrm{l})$, fenitrothion $(0.031 \mu \mathrm{g} / \mathrm{l})$, isoprothiolane $(0.027$ $\mu \mathrm{g} / \mathrm{l})$, flutolanil $(0.002 \mu \mathrm{g} / \mathrm{l})$, tolclofos methyl $(0.003 \mu \mathrm{g} / \mathrm{l})$, mepronil $(0.006 \mu \mathrm{g} / \mathrm{l})$, iprodione $(0.011 \mu \mathrm{g} / \mathrm{l})$ and isoxathion $(0.003 \mu \mathrm{g} / \mathrm{l})$ in Ishikari river water was reported by Kondoh et al. (2001).

Seasonal variations of pesticide concentrations were apparent at all the sampling sites (Fig. 3a). Pesticide concentrations were generally higher during growing season (April to September) and gradually decreased starting in October. The high concentrations in the growing season were probably due to the fact that the most of pesticides are used this period (Tanabe et al., 2001). Of the five sites, the Izumi, Hinotsume and Ochiai sites, had the highest concentrations throughout seasons. These three sites are located in agricultural and urban areas where various sources of pesticides are present. The main source of pesticides in Kurose River appears to be agricultural fields. This is based on the finding of a good correlation between monthly concentration of total pesticides (as 5 sites average) and corresponding monthly precipitation (Fig. 4), and the finding that there is an involvement of pesticides with soil mineral components such as $\mathrm{Na}^{+}, \mathrm{K}^{+}$and $\mathrm{Ca}^{2+}$ in the principal component analysis (Table 5). Several studies have shown that precipitation events increase the concentration levels of pesticides in stream in agricultural areas. After carbofuran was applied to an oilseed rape crop, its concentrations increased to biologically active levels during rainstorms (Matthiessen et al., 1995). In west England, relatively high concentrations of herbicides and insecticides were observed after heavy rainfall (Brooke and Matthiessen, 1991; Williams et al., 1991a, b; Matthiessen et al., 1992). Thus 


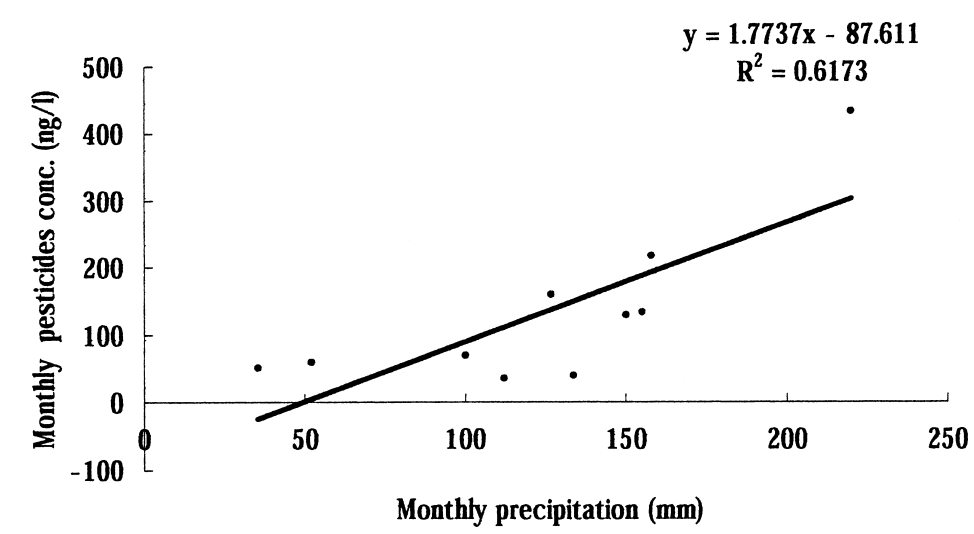

Fig. 4. Correlation between monthly concentration of total pesticides (average of 5 sites) and corresponding monthly atmospheric precipitation of Higashi-Hiroshima during the study period.

Table 5. Principal component analysis for 5 sites average of water quality data obtained during June 2001-January 2002 in Kurose River

\begin{tabular}{|c|c|c|c|c|c|c|}
\hline & \multicolumn{2}{|c|}{ Factor 1} & \multicolumn{2}{|c|}{ Factor 2} & \multicolumn{2}{|c|}{ Factor 3} \\
\hline Total variance $(\%)$ & 38.4 & & 19.2 & & 17. & \\
\hline \multirow{7}{*}{ Component $(r \geqq 0.5$ ) } & $\mathrm{K}^{+}$ & 0.92 & $\mathrm{Cl}^{-}$ & -0.88 & Nonylphenol & 0.82 \\
\hline & Precipitation & 0.91 & $\mathrm{NO}_{2}^{-}+\mathrm{NO}_{3}^{-}$ & 0.88 & $\mathrm{NH}_{4}^{+}$ & -0.77 \\
\hline & $\mathrm{Na}^{+}$ & 0.90 & $\mathrm{Mg}^{2+}$ & 0.77 & $\mathrm{SO}_{4}^{2-}$ & 0.70 \\
\hline & Pesticides & 0.82 & & & WT & 0.52 \\
\hline & DOC & 0.81 & & & & \\
\hline & $\mathrm{Ca}^{2+}$ & 0.78 & & & & \\
\hline & $\mathrm{H}^{+}$ & -0.56 & & & & \\
\hline
\end{tabular}

WT: water temperature; DOC: dissolved organic carbon.

we conclude that pesticide concentrations in Kurose River are determined by two processes: the time that the pesticides are applied to agricultural fields and the amount of precipitation, which washes the pesticides into the streams.

Simazine that was detected in this study is designated as a substance of environmental quality standards for the human health, and diazinon, propyzamide, fenitrothion, isoprothiolane and isoxathion are designated as monitoring needed substances by the Ministry of Environment, Japan. However, the standard values or guideline values of these substances in natural water (3 to $40 \mu \mathrm{g} / \mathrm{l})$ are much higher than the concentrations that we determined. Thus, these pesticides should have no adverse health effects in the Kurose River.
The total pesticide flux in Kurose River was considerably higher during the period of April to August and decreased after September (Fig. 5b). This is due to high water flow rates (Fig. 5a) and relatively high concentrations of detected pesticides during the spring and summer seasons. At Namitakiji site, the water flow was almost zero because of a pond structure at this site. Thus the flux of pesticides at this site was assumed to be zero. The flux of total fungicides over the study period was much greater than that of herbicides and insecticides at all sites (Fig. 6). This was because fungicides were detected at higher concentrations and higher frequencies than herbicides and insecticides. These fungicides were relatively widespread; possibly due to their uses to control 

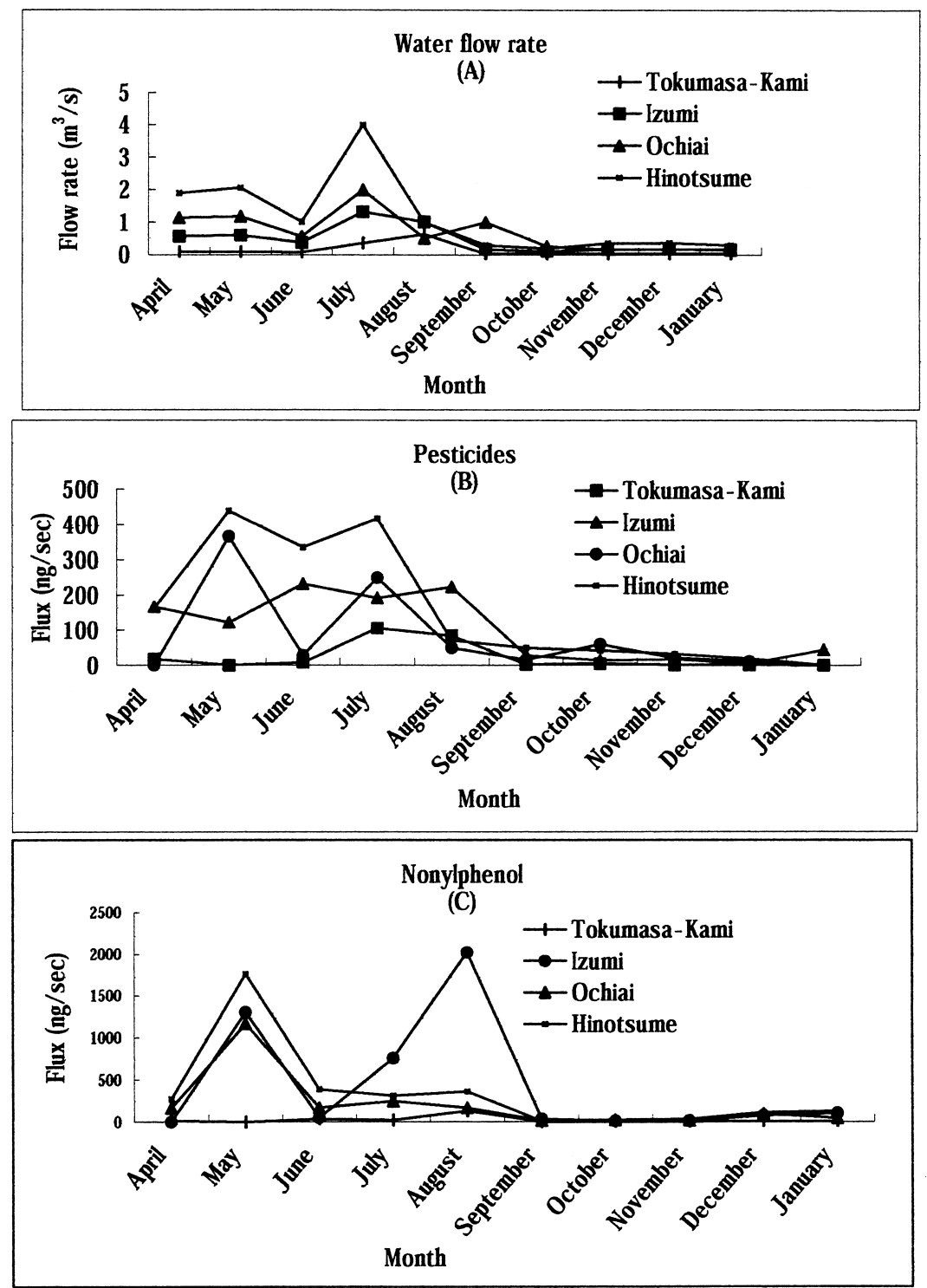

Fig. 5. Monthly water flow rate and fluxes of pesticides and nonylphenol at each sampling site in Kurose River.

wide range of fungal diseases for most crops, especially for the rice the common crop in this area. The flux of individual pesticides in the Kurose River near Ochiai site ranged from 0.00002$0.013 \%$ of estimated annual use in HigashiHiroshima (Table 6). The large variability in these percentages is not surprising in view of the considerable variability in (1) physical properties of pesticides (2) the application practices (Larson et $a l ., 1995)$, and (3) the effective dissipation processes during the transit time in the surface water (Sudo et al., 2002). These percentages were low compared with the previously published values (Larson et al., 1995). This can be due to many reasons, such as differences in the chemical and environmental properties of the pesticides, application practices, soil characteristics, topography and weather. The flux is also influenced by low 


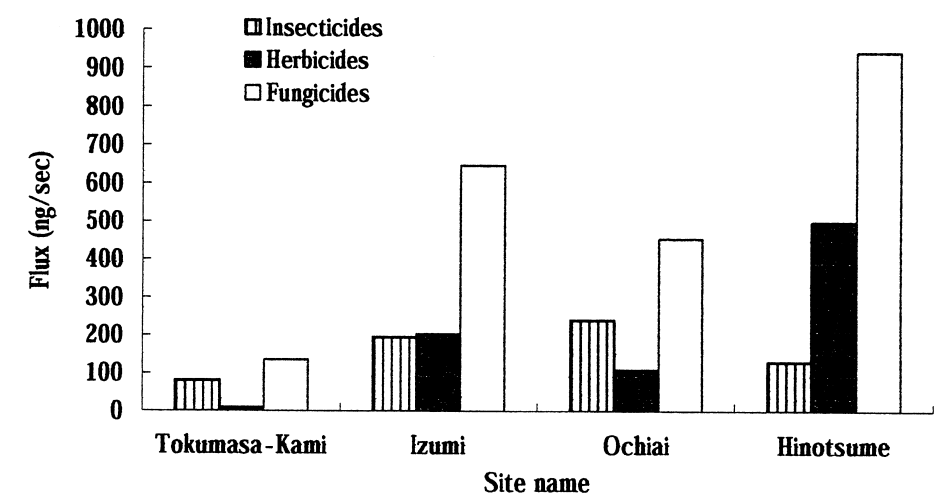

Fig. 6. The flux of total insecticides, herbicides and fungicides during April 2001-January 2002 in Kurose River.

Table 6. Amount of agricultural use in Hiroshima prefecture, estimated annual use in HigashiHiroshima (a), annual flux $(b)$ and the percentage of $(b)$ to $(a)$, for detected pesticides in Kurose River

\begin{tabular}{lcccc}
\hline & $\begin{array}{c}\text { Annual use in } \\
\text { Hiroshima }(1999-2000) \\
(\mathrm{kg})\end{array}$ & $\begin{array}{c}\text { Estimated annual use in } \\
\text { Higashi-Hiroshima (a) } \\
(\mathrm{kg})\end{array}$ & $\begin{array}{c}\text { Annual flux in } \\
\text { Kurose River (b) } \\
(\mathrm{kg})\end{array}$ & $\begin{array}{c}(\mathrm{b}) /(\mathrm{a}) \times 100 \\
\% \text { of amount use }\end{array}$ \\
\hline Pencycuron & 9300 & 650.35 & 0.00014 & 0.00002 \\
Simazine & 1200 & 83.92 & 0.00068 & 0.0008 \\
Propyzamide & 900 & 62.94 & 0.00034 & 0.0005 \\
Diazinon & 1700 & 1209.7 & 0.00017 & 0.00001 \\
Tolclofos-methyl & 600 & 41.96 & 0.00020 & 0.00047 \\
Metalaxyl & 2600 & 181.8 & 0.00076 & 0.00042 \\
Dithiopyr & 700 & 48.95 & 0.00023 & 0.00046 \\
Fenitrothion & 1300 & 90.91 & 0.00099 & 0.001 \\
Pendimethalin & 5200 & 363.64 & 0.00025 & 0.00007 \\
Methyldymron & 4100 & 286.71 & 0.00057 & 0.00019 \\
Butamifos & 300 & 20.98 & 0.00025 & 0.0012 \\
Flutolanil & 3200 & 223.78 & 0.00045 & 0.0002 \\
Isoprothiolane & 4000 & 279.72 & 0.00105 & 0.00037 \\
Triclopyr-ester & 1900 & 132.87 & 0.00042 & 0.00031 \\
Isoxathion & 15900 & 1111.8 & 0.00028 & 0.00002 \\
Mepronil & 100 & 6.99 & 0.00040 & 0.005 \\
Iprodione & 100 & 6.99 & 0.00096 & 0.013 \\
Pyridaphenthion & 100 & 6.99 & 0.00034 & 0.0048 \\
\hline
\end{tabular}

Estimated annual use of pesticides in Higashi-Hiroshima was calculated by using the ratio of agricultural area in HigashiHiroshima to that of Hiroshima prefecture.

water flow rate of Kurose River (estimated at 0.91 $\mathrm{m}^{3} / \mathrm{sec}$ as the average rate during the study period, based on data obtained by Hiroshima prefecture office). For comparison, the flow rate in the Seta River in Shiga prefecture in Japan is 90 $\mathrm{m}^{3} / \mathrm{sec}$ (Sudo et al., 2002).

\section{Nonylphenol}

Of the compounds investigated in this study, nonylphenol was detected with highest frequency (91.3\%) (Fig. 2). This may be because nonylphenol has many sources, such as detergents, emulsifiers, wetting and dispersing agents in pes- 


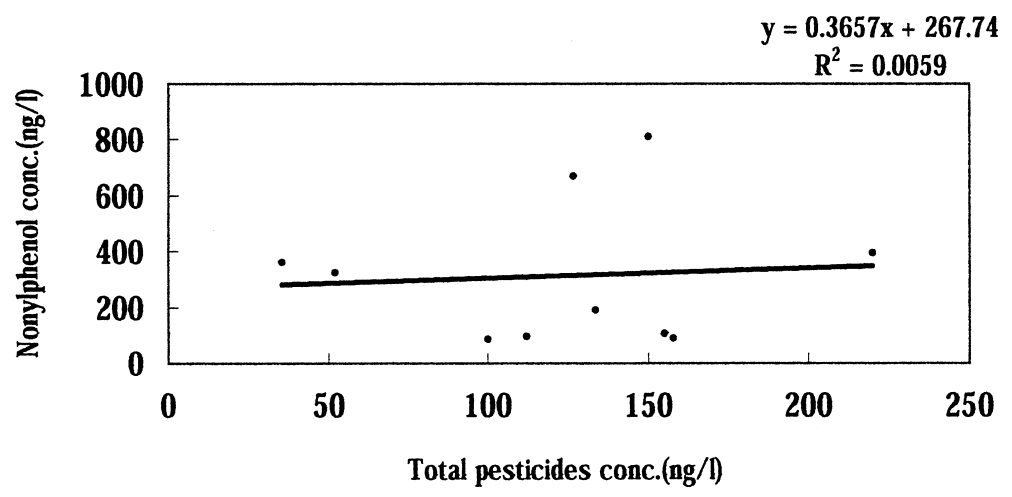

Fig. 7. Correlation between the concentration of total pesticides and nonylphenol (as 5 site averages) in Kurose River.

ticide formulations, and household products. Other studies also reported detecting nonylphenol at high frequencies in river water in Japan (Kojima and Watanabe, 1998; Isobe et al., 1999). Nonylphenol also showed higher mean concentration (305 ng/ 1) than that of individual pesticides at all sites (Table 4) due to the wide range of contamination sources and the heavy uses as household products. The Izumi, Ochiai and Hinotsume sites had the highest nonylphenol concentrations, followed by Tokumasa-Kami and Namitakiji sites. The higher concentrations of nonylphenol at Izumi site appear to be due to the wide range of potential nonylphenol sources at this site, which is near a densely populated urban and industrial area. Very high concentrations of nonylphenol were detected in May and August 2001 at Izumi site (Fig. 3b), which suggests the occurrence of one or more local specific sources of nonylphenol. However, the locations of these sources are unknown. The nonylphenol concentrations in the Kurose River are similar to those reported in other rivers in Japan (Isobe et al., 1999; Tsuda et al., 2000; Tabata et al., 2001).

The mean concentration of nonylphenol in the natural water including river, lake and sea waters in Japan (170 ng/l, $n=1574$, range <30-21000 $\mathrm{ng} / \mathrm{l}$ ) (Ministry of Environment Japan, 2001) is lower than the mean concentration $(305 \mathrm{ng} / \mathrm{l})$ in Kurose River. Also according to this same report the maximum concentration of nonylphenol that has no effects as an endocrine disrupter in fish is $608 \mathrm{ng} / \mathrm{l}$. The 10-month average concentration of nonylphenol at the Izumi site and spring and summer concentrations at some of the other sites, were higher than this level (Fig. 3b). This indicates that nonylphenol concentrations in the Kurose River may be occasionally hazardous to aquatic organisms, especially fish.

Pesticides are considered to be one of the sources of nonylphenol contamination in natural waters. Thomas et al. (2001) reported the occurrence of nonylphenol, as well as herbicides such as endosulfan sulfate and pendimethalin, in stream waters in south east England, possibly resulting from the use of NPEOs in pesticides formulations. Also NPEOs has been used in the formulation of insecticides such as aminocarb. Aminocarb has been used for control the spruce budworm in Canada and, after spraying, 4-nonylphenol was found at ppb levels in a forest stream (Sundaram et al., 1980; Fairchild et al., 1999). However, the correlation between total pesticides and nonylphenol concentrations (as 5 site averages) measured in this study was very weak (Fig. 7), which suggests that main sources of these pollutants are different from each other. The principal component analysis indicated that the concentration of nonylphenol is well correlated with the concentration of $\mathrm{SO}_{4}{ }^{2-}$ ion, which is a major component of wastewater. The Kurose River at Higashi-Hiroshima receives treated wastewaters 
from local community and local industries, as well as from many domestic sewage purifiers set up in individual houses. Thus we believe that the main sources of nonylphenol in the Kurose River are wastewaters discharged from various facilities as a result of human activities.

The flux of nonylphenol at three downstream sites was generally high from April to August and started to decrease from September during the study period (Fig. 5c). The flux of nonylphenol was highest at the Hinotsume, Izumi and Ochiai sites and this is well associated with the high water flow rates (Fig. 5a) and concentration levels recorded at these sites (Fig. 3b). At the TokumasaKami site, the flux is the lowest one and this is due to the low water flow rate and relatively low concentration of nonylphenol at this site. The flux of nonylphenol was comparable with that of the total pesticides and sometimes exceeds it at the three downstream sites, apparently because the nonylphenol concentrations were almost same as or higher than the total pesticide concentrations at these sites.

\section{Conclusions}

Nineteen pesticide compounds and nonylphenol were detected in Kurose River waters from both agricultural and urban areas during the study period. The concentration range of these compounds was at the ppt level. Many of the detected insecticides, fungicides and herbicides are common agricultural pesticides used in Hiroshima Prefecture. Particularly fungicides that are commonly used for crop protection were detected at high frequencies and at high concentration at all sites.

The detection frequency and concentration of nonylphenol were higher than individual pesticides at all sites, suggesting that the water pollution by nonylphenol is considerable and may be harmful to aquatic organisms at some sites in the Kurose River. The results obtained from the present study indicate that both agricultural and urban areas are sources of pesticides and nonylphenol contamination in the Kurose River.
Seasonal variation of pesticides and nonylphenol concentrations and fluxes indicated that spring and summer are the critical seasons for the occurrence of these pollutants in the Kurose River.

Acknowledgments-The authors are indebted to Dr. Kazuhiko Takeda, Graduate School of Biosphere Sciences, Hiroshima University for his help in collecting and analyzing water samples. We gratefully acknowledge Dr. Kazuto Takimoto, Faculty of Engineering, Hiroshima University for providing a flowmeter for water flow rate measuring. The authors are grateful to Mr. Masaaki Chiwa and Naosuke Ebihara for helping with the ion chromatography measurements. The authors also deeply thank Mr. Kazuo Yamamura for his help in the DOC analysis. The authors express their deep gratitude to the technical staff of Towa Kagaku Company, Hiroshima, for conducting solid phase extractions and GC-MS analyses.

\section{REFERENCES}

Ahel, M., Conrad, T. and Giger, W. (1987) Persistent organic chemicals in sewage effluents 3. Determination of nonylphenoxy carboxylic acids by high-resolution gas chromatography/mass spectrometry and high-performance liquid chromatography. Envir. Sci. Toxic. 21, 697-703.

Azevedo, D. A., Vinhas, T., Viana, P. and Barcelo, D. (2000) Monitoring the priority pesticides and other organic pollutants in river water from Portugal by gas chromatography-mass spectrometry and liquid chromatography-atmospheric pressure chemical ionization mass spectrometry. J. Chromatogr. 879, 1326.

Brooke, D. and Matthiessen, P. (1991) Development and validation of modified fugacity model of pesticide leaching from farmland. Pest. Sci. 31, 349-361.

Castilho, J. A. A., Fenzl, N., Guillen, S. M. and Nascimento, F. S. (2000) Organochlorine and Organophosphorus pesticide residues in the Atoya river basin, Chinandega, Nicaragua. Environ. Pollut. 110, 523-533.

Crisp, T. M., Clegg, E. D., Cooper, R. L., Wood, W. P., Anderson, D. G., Baetcke, K. P., Hoffmann, J. L., Morrow, M. S., Rodier, D. J., Schaeffer, J., Touart, E. L. W., Zeeman, M. G. and Patel. Y. M. (1998) Environmental endocrine disruption: An effects assessment and analysis. Environ. Health Perspect. 106, 11-56.

Fairchild, W. L., Swansburg, O. E., Arsenault, J. T. and Brown, S. B. (1999) Does an Association between Pesticide Use and Subsequent Declines in Catch of 
Atlantic Salmon (Salmo salar) Represent a Case of Endocrine Disruption? Environ. Health Perspect. 107, 349-358.

Hiroshima Prefecture Office (2002) Agriculture, Forestry and Fisheries in Hiroshima Prefecture, 55 pp. (in Japanese).

Isobe, T., Satoh, M. and Takada, H. (1999) Determination of nonylphenol by GC-MS in environmental samples in Tokyo. J. Jpn. Soc. Wat. Enviorn. 22, 118126 (in Japanese).

Itagaki, N., Nagafuchi, O., Takimoto, K. and Okada, M. (2000) Fate of pesticides in a shallow reservoir. Wat. Sci. \& Technol. 42, 217-222.

JPPA (Japan Plant Protection Association) (2000) Noyaku Yoran. Japan Plant Protection Association, Tokyo, Japan 737 pp. (in Japanese).

Kojima, S. and Watanabe, M. (1998) Distribution of alkylphenol polyethoxylate (APE) and their metabolites in aquatic environment in Nagoya City. Jpn. J. Wat. Pollut. Res. 21, 302-309 (in Japanese).

Kondoh, H., Fukuyama, R. and Liu, A. (2001) Simultaneous determination of pesticides and their seasonal variation in Ishikari River Basin. J. Environ. Chem. 11, 253-266 (in Japanese).

Larson, S. J., Capel, P. D., Goolsby, D. A., Zaugg, S. D. and Sandstrom, M. W. (1995) Relation between pesticides use and riverine flux in the Mississippi river basin. Chemosphere 31, 3305-3321.

Larson, S. J., Gilliom, R. L. and Capel, P. D. (1999) Pesticides in streams of united States-initial results from the national water quality assessment program. U.S. Geological Survey Water-Resources Investigations Report 98-4222.

Leonard, R. A. (1990) Movement of pesticides into surface waters. Pesticides in Soil Environment: Processes, Impacts, and Modeling (Cheng, H. H., ed.), 303-349, Soil Science Society of America Publishers, Madison, WI.

Majewski, M. S., Foreman, W. T. and Goolsby, D. A. (2000) Pesticides in the atmosphere of the Mississippi River Valley, Part I-rain. Sci. \& Total Environ. 248, 201-212.

Manzano, M. A., Perales, J. A., Sales, D. and Quiroga, J. M. (1999) The effect of temperature on the biodegradation of nonylphenol polyethoxylate in river water. Wat. Res. 33, 2593-2600.

Matthiessen, P., Allchin, C., Williams, R. J., Bird, S. C., Brooke, D. and Glendinning, P. J. (1992) the translocation of some herbicides between soil and water in a small catchment. J. Inst. Wat. Environ. Manago. 6, 496-504.

Matthiessen, P., Sheahan, D., Harrison, R., Kirby, M., Rycroft, R., Trunbull, A., Volkner, C. and Williams, R. (1995) Use of a Gammarus pulex bioassay to mea- sure the effects of transient carbofuran runoff from farmland. Ecotoxicol. Environ. Saf. 30, 111-119.

McLeese, D. W., Zito, D. W., Sergeant, D. B., Burridge, L. and Metcalfe, C. D. (1981) Lethality and accumulation of alkylphenols in aquatic fauna. Chemosphere 10, 723-730.

Ministry of Environment Japan (2001) Report for the endocrine disruption effect of nonylphenol on fish, August 44 pp. (in Japanese).

Mol, H. G. J., Sunarto, S. and Steijger, O. M. (2000) Determination of endocrine disruptors in water after derivatization with N-methyl-N(Tretbutyldimethyltrifluoroacetamide) using gas chromatography with mass spectrometric detection. J. Chromatogr. 879, 97-112.

Mopper, K. and Zhou, X. (1990) Hydroxyl radical photoproduction in the sea and its potential impact on marine processes. Science 250, 661-664.

Numabe, A., Inoue, T. and Ebise, S. (1992) Estimation of runoff amounts of pesticides applied after transplanting of rice plant by Drainage River. J. Wat. Environ. 15, 662-671 (in Japanese).

Odanaka, Y., Taniguchi, T., Shimamura, Y., Iijima, K., Koma, Y., Takechi, T. and Matano, O. (1994). Runoff and leaching of pesticides in golf course [sic]. $J$. Pest. Sci. 19, 1-10.

Okumura, T. and Nishikawa, Y. (1995) Determination of organophosphorus pesticides in environmental samples by capillary gas chromatography-mass spectrometry. J. Chromatogr. 709, 319-331.

Petroff, R. (2000) Water quality and pesticide performance. Education Specialist Montana State University Extension Service.

Richards, R. P. and Baker, D. B. (1993) Pesticides concentration patterns in agricultural drainage networks in the lake Eire basin. Environ. Toxicol. \& Chem. 12, 13-26.

Samia El-Kabbany, Rashed, M. M. and Zayed, M. A. (2000) Monitoring of the pesticides levels in some water supplies and agricultural land, in El-Haram, Giza (A.R.E.). J. Haza. Mat. 72, 11-21.

Scott, M. J. and Jones, M. N. (2000) The biodegradation of surfactants in the environment. Bioc. Biophy. Acta 1508, 235-251.

Sudo, M., Kunimatsu, T. and Okubo, T. (2002) Concentration and loading of pesticide residues in Lake Biwa basin (Japan). Wat. Res. 36, 315-329.

Sundaram, K. M., Szeto, S., Hindle, R. and MacTavish, D. (1980) Residues of nonylphenol in spruce foliage, forest soil, stream water and sediment after its aerial application. J. Environ. Sci. \& Health 15, 403419.

Tabata, A., Kashiwada, S., Ohnishi, Y., Ishikawa, H., Miyamoto, N., Itoh, M. and Magara, Y. (2001) 
Estrogenic influences of estradiol-17â, $p$ nonylphenol and bis-phenol-A on Japanese Medaka (Oryzias latipes) at detected environmental concentrations. Wat. Sci. \& Technol. 43, 109-116.

Tamura, H., Maness, S. C., Reischmann, K., Dorman, D. C., Gray, L. E. and Gaido, K. W. (2001) Androgen receptor antagonism by organophosphate insecticide fenitrothion. Toxicol. Sci. 60, 56-62.

Tanabe, A., Mitobe, H., Kawata, K., Yasuhara, A. and Shibamoto, T. (2001) Seasonal and spatial studies on pesticide residues in surface waters of Shinano River in Japan. J. Agric. Food Chem. 49, 3847-3852.

Thomas, K. V., Hurst, M. R., Matthiessen, P., Sheahan, D. and Williams R. J. (2001) Toxicity characterisation of organic contaminants in stormwaters from an agricultural headwater stream in South East England.
Wat. Res. 35, 2411-2416.

Tsuda, T., Takino, A., Kojima, M., Harada, H., Muraki, K. and Tsuji, M. (2000) 4-Nonylphenol and 4-tretoctyphenol in water and fish from rivers flowing into Lake Biwa. Chemosphere. 41, 757-762.

Williams, R. J., Bird, S. C. and Clare, R. W. (1991a) Simazine concentrations in a stream draining an agriculture catchment. J. Inst. Wat. Environ. Manago. 5, 80-84.

Williams, R. J., Brooke, D. N., Glendinning, P. J., Matthiessen, P., Mills, M. J. and Turnbull, A. (1991b) Measurement and modeling of pesticides residues at Rosemaund Farm. Proceedings of British Crop Protection Conference, Brighton 2, 507-514, British Crop Protection Council, Farnham. 